\title{
The Effect of Intellectual Humility on Professional Knowledge in Preschool Teachers: The Dual Mediating Effects of Self-Development Needs and Teacher's Teamwork
}

\author{
Yumi Kim ${ }^{1}$, Daeun Park ${ }^{2}$ \\ Doctoral Student, Department of Child Welfare, Chungbuk National University, Chungbuk, Korea ${ }^{1}$ \\ Assistant Professor, Department Psychology, Sungkyunkwan University, Seoul, Korea ${ }^{2}$ \\ 유아 교사의 지적 겸손성향이 전문적 지식에 미치는 영향: \\ 자기개발욕구와 동료교사 협력의 이중매개효과 \\ 김유미 ${ }^{1}$, 박다은 $^{2}$ \\ 충북대학교 아동복지학과 박사과정생, 성균관대학교 심리학과 조교수 2
}

Objectives: Intellectual humility refers to a tendency to recognize and accept that one's personal beliefs or knowledge may be fallible and limited. The purpose of this study is to examine whether preschool teachers' intellectual humility predicts self-development needs and teamwork, which in turn, predict professional knowledge. In other words, the current study investigates the dual mediating effects of self-development needs and teamwork in the relationship between intellectual humility and professional knowledge in preschool teachers.

Methods: A total of 206 teachers across 32 preschools participated in this study. The participating teachers completed questionnaires on intellectual humility, self-development needs, teamwork, and professional knowledge. SPSS 25.0 was used to test the mediating effect of self-development needs and teamwork on the relationship between intellectual humility and professional knowledge in teachers. In addition, PROCESS macro version 3.4 (Hayes, 2017) was used to confirm the indirect effect.

Results: The teachers' intellectual humility predicts professional knowledge via self-development needs and teamwork. In other words, teachers who acknowledge their own intellectual limits and are open to new experiences and learning opportunities have a higher level of professional knowledge in teaching, and this relation is mediated by both self-development needs and teamwork. The bootstrapping results also suggest that the indirect effect is statistically significant.

Conclusion: This study is the first to introduce and apply a new concept of intellectual humility in a Korean sample. By showing the relationship between intellectual humility, self-development needs, teacher teamwork, and professional knowledge, the study highlights the importance of intellectual virtue in preschool teachers.

Keywords: intellectual humility, self-development needs, teacher teamwork, professional knowledge

Corresponding Author: Daeun Park, Assistant Professor, Department of Psychology, 25-2, Sungkyunkwan-ro, Jongno-gu, Sungkyunkwan University, Seoul, Korea

E-mail: daeunp@skku.edu
(C)The Korean Association of Child Studies

This is an Open Access article distributed under the terms of the Creative Commons Attribution Non-Commercial License (http:// creativecommons.org/licenses/by-nc/4.0) which permits unrestricted noncommercial use, distribution, and reproduction in any medium, provided the original work is properly cited. 


\section{Introduction}

"곡식은 익을수록 고개를 숙인다.", "물은 깊을수록 소리가 없 다.” 등은 겸손의 미덕을 뜻하는 속담이다. 겸손이란 남을 존 중하고 자기를 내세우지 않는 태도로, 다른 사람을 대하는 데 있어 공정하고 진솔한 경향을 뜻한다(Aston \& Lee, 2007). 다시 말해 겸손은 자신의 능력을 낮추어 나타내고 자신에 대한 평 가를 객관적으로 인지하고 받아들이는 태도라 할 수 있다(S.W. Lee, 2020). 최근, 이러한 겸손을 지적능력에 적용한 개념 이 소개되었으며, 이를 Intellectual Humility (Krumrei-Mancuso, 2017; Porter, 2015; Porter \& Schumann, 2018), 즉 지적겸손이 라 일컫는다. 지적겸손 성향이 높은 사람들은 자신이 알고, 믿 고 있는 것들이 사실과는 다를 수 있음을 인정하고 타인의 의 견을 존중하는 경향성이 있다(Leary et al., 2017). 본 연구에서 는 지적겸손이 유아 교사의 자기개발, 동료교사협력, 전문성 에 미치는 영향성을 탐색함으로써, 지적겸손의 개념을 국내 학계에 최초로 소개하고 유아 교사의 전문성 개발에 필수적인 역량임을 검증하고자 한다.

현대의 유아교육 기관은 단순히 영유아를 보육하고 돌보 는 양육기관에서 더 많은 사회적 요구를 반영하여 영유아에게 다양한 경험과 잠재력을 발달시키는 장소로 인식이 변화하고 있다(J. M. Kim, 2019). 또한 폭발적으로 늘어나는 지식과 정 보의 현대사회에서 교육개혁의 필요성과 교사의 질을 향상하 는 문제는 지속적으로 제기되어왔다(Oh, 2020). 이에 따라 보 육의 질적 서비스에 관한 관심과 요구가 증가하였으며, 더불 어 급변하는 보육정책과 새로운 세대의 학부모들에게도 민감 하게 반응해야 하는 시대에 직면하였다(Y. J. Kim, 2001). 교육 기관 안에서 영유아들을 책임지는 교사에 대한 관심이 증가하 고, 교사는 부모와 더불어 제 2 의 양육자로서의 역할이 요구됨 에 따라 교사의 역할이 매우 다양하고 복잡해졌으며, 이에 교 사의 전문성 함양의 필요성과 중요성 또한 강조되었다(J. M. Lee, 2017).

교사의 전문성은 시대의 흐름과 사회문화적 변화를 반영하 여 다양하게 연구되고 있으며, 전문적 지식과 전문가의 개념, 사회의 영향력에 대한 책임감, 전문직업인으로서의 열정과 헌 신, 그리고 그 분야에 대한 자율성이라는 개념적 특성을 가진 다(Oh, 2020). 유아 교사는 담당하는 영유아의 연령에 대한 지 식과 기술수행뿐만 아니라 영유아 개개인의 발달적 특성을 파 악하고 있어야 하는 등 높은 전문성을 요하는 직종이다(G.-Y. An, 1998). 전문성이란 전문적 직업에서의 태도와 행동양식을 포함하는 개인적인 특성으로, 그 전문적인 태도는 자신의 일
의 가치에 관한 신념이며 전문적 지식에 근거하여 이루어진다 (Lindsay \& Lindsay, 1987; Cho에서 재인용, 2012). 특히, 유아 교사에게 전문성은 충분한 경험을 통해 유아 교사로서의 교육 적 임무를 수행하는 정도를 나타내며(Y.-R. Choi, 2018), 유아 교사의 전문성은 현재 맡은 업무를 전문적으로 여기고 새로운 학습이론과 그에 따른 기술을 재교육을 통해 끊임없이 학습함 으로써 향상된다(S. H. Lee, 2011).

유아 교사의 전문성에 영향을 미치는 변인으로는 직무만족, 직무 스트레스, 이직의도, 소진 등과 같은 교사의 심리적, 정서 적 요인이 있다(J. N. An, 2017; Y. Kwon, 2013; J. Lee, 2010; Y. S. Park, Song, \& Lee, 2018; Yoon, 2017; You, 2011). 더불어 교사 개 인의 성격과 자기개발욕구, 행복감, 교사효능감, 자아 탄력성 과 같은 개인 내적인 요인 역시 전문성에 영향을 미치는 것으 로 나타났다(Y.-R. Choi, 2018; J. Kim, 2017; E. Y. Park, 2018; S. Park, 2019; Son, 2014). 그 중 특히 자기개발 욕구와 같이 교사 로서의 내적인 동기가 교사의 전문성과 관련이 깊은 것으로 나 타났다(S. Jeon, 2019; J. M. Kim, 2019; Y. Kim, 2019; E. Y. Park, 2018). 다시말해, 교사의 자기개발욕구가 높을수록 유아 보육 및 교육에 대한 교사의 전문성이 높게 나타난다.

교사의 자기개발이란 스스로가 자신을 성장시키고, 발전하 고자 하는 향상 의욕을 갖고 스스로를 변화하려는 노력을 의 미하며(S.-H. Kim, 2003), 교사의 자기개발은 직무수행에 있어 당연한 책무이다. 교사가 지녀야 하는 교육적 지식은 시대적 변화나 사회적 요구에 따라 변화하고 발전하므로 적응하고 꾸 준히 노력해서 익혀야 하는 과정이다(B. Y. Park, 2013). 유아에 게 적절한 프로그램과 좋은 교육환경이 갖추어져 있어도 유아 교사의 자기개발 욕구가 낮고 전문가로서의 그 역할을 제대로 발휘하지 못한다면 교육적 효과는 기대하기 어렵다(H.-J. Kim \& Shin, 2008). 따라서, 교사의 자기개발욕구는 보육 및 교육 서비스의 질을 향상할 뿐만 아니라(S. H. Lee, 2015), 교사로서 의 효능감과 행복감을 높이는 등 개인 삶의 질적 향상과도 관 련이 있는 것으로 나타났다(J. E. Choi, 2018; Kang, 2015). 이러 한 자기개발에 대한 욕구는 타인의 강요 없이 교사의 내재적 동기에 의해 이루어지는 것이므로 교사의 자발적인 노력이 중 요한 요소이다(J. M. Kim, 2019; E. Y. Park, 2018). 이에, 교사의 자기개발 욕구를 이해하기 위해서는 교사 개개인 스스로가 지 식을 습득하고자 하는 욕구와 전문적 지식수준을 향상하고자 하는 개인적 성격 특성에 주목할 필요가 있다.

무엇이 교사의 내재적 자기개발 욕구를 예측하는가? 개 인의 내재적 동기와 관련이 깊은 성격 특성 중 지적겸손 (intellectual humility)성향은 자신의 인지능력과 지식이 제한적 
이고 불완전함을 받아들이고 다른 사람의 지적능력을 인정하 는 것을 의미한다(Krumrei-Mancuso, 2017; Porter \& Schumann, 2018). 사람들이 사실이라고 믿는 것 중의 많은 부분은 불완 전하거나, 편향이 존재하거나, 틀린 것들임에도 불구하고 (Gilovich \& Griffin, 2010), 사람들은 자신이 믿는 것과 아는 것에 대한 확신을 가지고 있다(Koehler, 1991; Moore \& Healy, 2008). 대부분의 사람들이 이러한 경향성을 가지고 있긴 하지 만, 사람마다 자신이 믿고, 아는 것이 틀릴 수도 있음을 인정하 는 정도에는 차이가 난다. 지적겸손 성향은 이렇듯 자신의 지 적인 한계를 인정하고 다른 사람의 지식을 가치 있는 것으로 여기는 개인의 성격적 특성이다. 예를 들면, 모르는 것이 있을 때 그것을 인정하고 받아들일 줄 아는지, 다른 사람들의 지적 능력을 인정하고 칭찬하는지, 타인의 비판과 조언을 적극 반 영하는지 등이 지적겸손 성향에 포함된다. 지적겸손 성향은 겸손이라는 전반적인 태도보다는 지적영역에 초점을 맞춘 것 으로 더욱 구체적인 개인의 성향이다(Davis et al., 2016; Gregg \& Mahadevan, 2014).

선행연구에 따르면 지적으로 겸손한 사람은 그렇지 않은 사람들에 비해 배움에 대한 욕구가 더 크고, 새로운 정보를 얻 는 것에 큰 흥미를 보이며 모르는 것이 있으면 배워서 알아가 려는 의욕도 더 높은 것으로 나타났다(Leary et al., 2017; Porter, 2015). 지적겸손 성향이 높은 사람은 새로운 지식을 탐구하고 자 하는 내재적 동기와 학업 성취가 높다(Porter \& Schumann, 2018). 더불어, 지적겸손 성향이 높을수록 자신의 인지적 한계 를 인식하고, 자신의 신념에 방어적이지 않은 자세를 가져 타 인의 관점을 존중하는 특성이 있다(Krumrei-Mancuso, 2017). 또한 지적겸손 성향이 높은 사람이 자신의 신념이나 가치로 다른 사람을 평가하는 경향이 덜 하고, 자신의 생각에 반대되 는 의견에도 화를 내지 않고, 다른 의견을 개방적으로 수용한 다(Davis et al., 2016; Leary et al., 2017). 따라서 지적겸손 성향 은 자신의 믿음, 견해, 지식에 대한 불완전성을 얼마만큼 인정 하는지를 넘어 다른 사람의 의견과 견해에 대한 개방성과 수 용에도 영향을 미치기에 타인과의 관계에도 영향을 미칠 수 있다(Leary et al., 2017).

앞서 살펴본 바와 같이 지적겸손 성향이 높은 사람은 새로 운 지식을 탐구하고자 하는 욕구가 높으며, 타인의 견해에 개 방적이라는 실증적 연구결과와 새로운 정보에 흥미를 보이며, 배움에 긍정적인 태도를 보이는 지적겸손 성향의 정의적인 측 면을 고려해 볼 때, 지적겸손의 성향이 높은 교사는 자기개발 욕구와 전문성이 높을 것으로 예측해 볼 수 있다. 구체적으로, 지적겸손성향이 높은 교사일수록 스스로가 더 나은 교육을 위
해 노력하려는 자기개발욕구가 높을 것이며, 이는 높은 전문 성으로 이어질 수 있을 것으로 예상해 볼 수 있다. 이는 교사의 지적겸손 성향이 자기개발 욕구를 매개로 전문성에 영향을 미 칠 수 있다는 것을 시사한다.

한편, 개인 내적(intrapersonal)인 발전을 꾀하는 자기 개발 욕구뿐만 아니라 주변인들과 긍정적인 대인관계 (interpersonal) 또한 교사의 지적겸손성향과 전문성과의 관계 를 매개할 수 있다. 대부분 교육기관이 그러하듯 유아교육기 관에서 동료 교사는 실제적인 지식과 경험을 공유하는 중요한 인적자원이다(Schaufeli \& Greenglass, 2001). 교사는 직무 특성 상 동료 교사들과 함께 역할을 나누어 연구하고 업무를 수행 함으로써 그 목적을 달성하는 경우가 많다(S.-H. Kwon \& Kim, 2013). 특히, 비교적 규모가 작고, 대부분이 여성으로 구성되 며, 교사들 간의 관계가 밀접한 영유아 교육기관의 특징을 고 려해 볼 때, 동료교사와의 협력은 유아 보육과 교육의 질을 결 정하는데 매우 중요하다고 할 수 있다(M. Kim, 2011).

동료교사 협력은 교사들간의 의사소통 및 전문지식의 공 유를 원활하게 하여 교사의 전문성 향상을 도모하기도 한다 (Goddard, Goddard, \& Tschannen-Moran, 2007; Sung, 2018). 동 료교사와의 협력관계를 통해 교사는 새로운 정보나 지식을 접하게 되고, 동료교사의 지지에 힘입어 새로운 교수법을 시 도해 보는 등 전문성 있는 교사로 성장할 수 있다(E. M. Jeon, 2017; M. S. Lee, 2002; J. H. Park, Song, \& Lee, 2016). 더불어, 유아 교사의 교사협력관계는 교사효능감과 부모-교사 협력관 계와 정적인 상관이 있는 것으로 나타나 유아 교사가 자신의 교수 능력에 대한 믿음과 자신감을 가지고 유아와 가족을 지 원할 수 있는 능력을 갖춘 전문성 높은 교사로 성장하는데 동 료교사와의 협력관계가 필수적임을 시사한다(J. Kim, 2019; S.-H. Kwon \& Kim, 2014).

어떤 특성을 가진 교사들이 동료와 긍정적인 협력관계를 형성하고 유지할까? 유아 교사의 동료협력 관계를 예측하는 요인에 관한 연구는 비교적 제한적이다. 한 연구에 따르면 자 신뿐만 아니라 타인의 정서를 인식하고, 이해, 판단, 조절하는 능력인 정서지능이 높은 교사일수록 동료와 원활한 협력관계 를 유지하는 것으로 나타났다(Ryu \& Kang, 2015). 더불어 자 발적이고 독립적으로 전문성 향상을 위해 계획, 실천, 평가에 참여하는 자기장학을 하는 교사일수록 동료 교사들과 기관의 비전을 공유하고, 수업에 관한 주제와 방법을 거리낌 없이 공 유하는 상호협력적인 관계를 형성한다(Oh, 2020).

비록 자기장학은 스스로의 발전을 위한 계획, 실행, 평가 를 거치는 행동적인 측면에 초점이 맞춰진 반면, 지적겸손은 
개인의 신념 및 성격 특성이라는 점에서 두 개념 간의 차이가 존재하지만 두 개념 모두 외부 강요 없이 스스로를 성장시키 고자 한다는 내적인 동기가 전제된다는 점에서 유사하다. 따 라서, 자기장학과 동료교사 협력관계의 정적인 상관을 보여 준 선행연구(Oh, 2020)와 지적겸손이 높은 사람들이 타인의 의견에 개방적이고 수용적이라는 선행연구(Davis et al., 2016; Leary et al., 2017)를 토대로 새로운 지식과 경험을 기꺼이 받아 들이고자 하는 지적겸손이 높은 교사일수록 긍정적인 동료협 력 관계를 형성할 수 있다는 것을 유추해 볼 수 있다.

앞선 내용을 종합해 보면 자신의 인지적 부족함을 인정하 고 새로운 지식을 탐구하고자 하는 지적겸손 성향이 높은 교 사일수록 자신을 성장시키고 발전하고자 하는 자기개발 욕구 가 높을 것으로 예측해 볼 수 있다. 더불어, 지적겸손이 높은 개인이 타인의 의견에 수용적인 태도를 보인다는 점을 고려해 보면, 지적겸손이 높은 교사들은 동료와의 긍정적인 협력관 계를 유지할 것임을 예측해 볼 수 있다. 자기개발 욕구와 긍정 적인 동료교사 협력관계가 교사 전문성과 정적인 상관을 갖는 다는 선행연구(E. M. Jeon, 2017; H.-J. Kim \& Shin, 2008; M. S. Lee, 2002; S. H. Lee, 2015)를 토대로, 유아 교사의 지적겸손은 자기개발 욕구와 동료교사 협력을 매개로 교사 전문성에 영향 을 미칠 수 있음을 예측해 볼 수 있다.

본 연구에서는 교사의 전문성 발달이 업무를 수행하는 동 안에 그 고유업무와 관련된 기술, 지식, 태도, 신념, 행동, 가치 관, 자질과 능력을 발달시키는 것(Y. S. Lee, 2001)이라는 측면 에서 교사의 전문성을 전문적 지식으로 측정하여 사용하고자 한다. 본 연구는 지적겸손 성향이라는 새로운 개념을 국내 학 계에 최초로 소개함과 동시에 교사의 전문성 함양과 연관된 교사의 성격적 특성을 밝힌다는 점에서 이론적 의의가 있다. 더불어, 교사의 전문적 지식의 향상을 위해 인지적 겸손뿐만 아니라 자기개발 욕구와 동료교사협력에 대한 개입의 중요성 을 밝힘으로써 이를 교사교육에 활용하여 유아의 건전한 성장 에 이바지하고자 한다.

\section{연구문제 1}

유아 교사의 지적겸손 성향, 자기개발욕구, 동료교사협력, 전 문적 지식 간의 관계는 어떠한가?

\section{연구문제 2}

유아 교사의 지적겸손 성향이 전문적 지식에 미치는 영향에 대한 교사의 자기개발욕구와 동료교사 협력의 이중매개 효과 가 유의한가?

\section{Methods}

\section{연구대상}

본 연구는 대학의 연구윤리위원회의 승인을 받아 이루어졌으 며, 충청북도에 소재한 유치원과 어린이집 32 개소에 재직 중 인 교사들을 대상으로 진행되었다. 자료는 질문지 조사방법으 로 수집하였으며 총 300 부의 질문지 중 210 부(70\%)의 교사 설 문지가 회수되어 그 중 불성실 응답 4 부를 제외한 206부가 분 석에 활용되었다.

교사의 평균 연령은 35.4 세 $(S D=8.80)$ 로 나타났으며, 연령 범위는 20 대 $31.6 \%, 30$ 대 $36.4 \%, 40$ 대 이상 $32 \%$ 로 30 대의 비 율이 가장 높았다. 성별은 전체 참여교사 206명 중에서 남자 가 1 명으로 $0.5 \%$, 여자가 205명으로 $99.5 \%$ 의 비율로 나타났 다. 교사의 최종학력은 전문대 졸업 이하가 $65 \%$, 대학교 졸업 이상이 $35 \%$ 로 나타나 전문대 졸업 이하가 더 높은 비율을 보 였고, 유아 교사의 총 경력 평균은 6년 6개월 $(S D=4.49)$ 이다. 교사가 근무하고 있는 기관의 설립유형으로는 국공립 어린이 집과 단설 유치원을 포함하는 지원시설이 $52 \%$, 민간 사립기 관을 포함하는 미지원시설이 $47.6 \%$ 로 정부의 지원을 받는 시 설의 비율이 가장 높게 나타났다.

\section{연구도구}

본 연구에서는 유아 교사의 지적겸손 성향, 자기개발욕구, 동 료교사협력, 전문적 지식을 측정하기 위해 다음의 척도를 사 용하였다. 모든 척도는 교사에 의해 보고되었다.

\section{지적겸손성향}

교사의 지적겸손 성향을 측정하기 위해 Porter와 Schumann (2018)이 개발한 척도를 번역하여 사용하였다. 지적겸손 성향을 측정하는 문항은 "나는 내가 무언가 모르는 것이 있다면 그것을 인정하려고 한다.", "나는 다른 사람들의 지적능력에 대해 칭찬 하는 것을 좋아한다." " "나는 나의 지적 발전을 위해 나의 약점을 고려한다." "나는 내 생각에 대한 비판적인 피드백도 적극 반영 한다.", "나는 어떤 주제에 나보다 더 잘 아는 사람이 있다면 그 것을 인정한다.", "나는 때때로 다른 사람의 지적능력에 감탄한 다.”로 총 6문항이다. 응답 방식은 Likert식 5점 척도로 전혀 그렇 지 않다(1점)부터 매우 그렇다(5점)로 평정되며, 점수가 높을수 록 지적겸손 성향이 높음을 의미한다. 내적 합치도는 .79이다. 
자기개발욕구

유아 교사의 자기개발 욕구를 측정하기 위하여 선택한 검사척 도는 Y. S. Lee (2001)의 자기개발 영역과 선행연구 자료를 참 고하여 S. H. Lee (2015)가 영유아 교사의 상황에 맞게 수정.보 완한 교사용 자기개발욕구 평정척도를 사용하였다. 그중 본 연구와 관계된 측정 도구의 하위요인 중 교사의 직무수행능 력과 관련된 '전문성 영역'을 사용하였다. 세부적으로는 “나는 요즘 영유아 발달의 이해와 아동학에 필요성을 느끼며 관심이 있다.", “나는 요즘 생활지도에 어려움을 느끼며 지도방법 개 선을 위한 방안에 관심을 가지고 노력한다.”를 포함하는 12 문 항으로 이루어졌다. 이에 응답방식은 5단계의 Likert식 척도로 전혀 그렇지 않다(1점)부터 매우 그렇다(5점)로 배점을 하고, 점수가 높을수록 자기개발 욕구가 높음을 의미한다. 내적합치 도는 .90 이다.

\section{동료교사협력}

동료교사 협력을 측정하기 위해 Finkelstein (1981), Lord (1994), Sergiovanni (1992), DeShaw (2009)의 변인들을 참고하여, Shah (2011)의 Teacher Collegiality Scale (TCS)를 중심으로 S.-H. Kwon과 Kim (2013)의 교사협력 측정도구를 J. Lee (2014)가 수 정.보완한 것을 사용하였다. 세부적으로는 "나는 학급경영에 대한 아이디어와 전문지식을 다른 교사들과 공유한다.", "나 는 동료교사와 함께 일을 하면 그들로부터 배울게 많다고 생 각한다." "나는 서로 도움을 주고받는 관계를 맺으며 교육업 무와 행정 업무를 함께 수행한다.” 등을 포함하는 20 문항으로 이루어졌다. 이에 응답방식은 5단계의 Likert식 척도로 전혀 그렇지 않다(1점)부터 매우 그렇다(5점)로 배점을 하고, 점수 가 높을수록 동료교사협력이 잘 이루어짐을 의미한다. 내적합 치도는 .93 이다.

\section{교사의 전문적 지식}

교사의 전문적 지식의 수준을 Lindsay와 Lindsay (1987)의 전문 성 인식 도구를 기초로 하여 Cho (2012)가 수정-보완한 영유아 교사의 전문성 인식 척도를 사용하여 하위요인 중 본 연구와 관련 있는 '전문적 지식'을 사용하였다. 이 척도는 적합한 교수 법과 전문지식적용의 가능 여부와 정보를 지속적으로 습득하 고 학부모에게 유아발달 및 문제에 대한 상담 가능 여부를 포 함한다. 이에 예를 들면, "유아발달에 적합한 교수 방법을 알
고 있다.”를 포함하는 질문 2가지와 “학부모들에게 유아발달 및 문제에 대해 상담을 할 수 있고, 조언할 수 있다.”를 묻는 2 가지 질문 등 총 4문항으로 구성되어 있다. 응답방식은 5단계 의 Likert식 척도로 전혀 그렇지 않다(1점)부터 매우 그렇다(5 점)로 배점을 하고, 점수가 높을수록 교사가 스스로 지각한 전 문적 지식의 수준이 높음을 의미한다. 내적 합치도는 .77이다.

\section{연구절차}

본 연구에 앞서 교사 대상 질문지 문항에 대한 적절성과 이해 도 및 소요시간을 알아보기 위하여 충청북도에 소재한 어린 이집 3개소를 선정하여 2019년 6월 24일부터 28일까지 교사 30 명을 대상으로 예비조사를 진행하였다. 조사 결과 교사 대 상 질문지의 소요 되는 시간은 약 15 분 정도였으며, 문항의 진 술 방식 등 실시에 문제가 없음으로 판단되어 본 조사를 진행 하였다. 본 조사는 2019년 8월 19일부터 9월 16일까지 충청북 도에 소재 유치원과 어린이집에 재직 중인 교사 300 명을 대상 으로 실시하였다. 질문지는 연구자가 각 기관에 직접 방문하 여 기관장과 교사에게 연구의 목적과 질문지 응답 방법을 설 명하였으며, 설문에 동의하는 교사들에게 동의서에 서명을 받 고 교사가 직접 질문지에 응답하도록 하였다. 응답한 질문지 는 연구자가 직접 기관에 방문하여 질문지를 수거하였다.

\section{자료분석}

본 연구는 수집된 자료의 분석을 위해 SPSS 25.0 프로그램 (IBM Co., Armonk, NY)을 사용하였다. 우선적으로 SPSS를 사 용해 변인들 간의 상관분석을 실시하였다. 그 후, 유아 교사의 지적겸손 성향과 자기개발 욕구, 동료교사 협력이 교사의 전 문적 지식 수준에 미치는 영향을 알아보기 위하여 PROCESS macro version 3.4 (Model 4; Hayes, 2017)를 사용하여 분석하였 으며, 간접효과의 유의성을 검증하기 위하여 부트스트래핑 (표본수 5,000)을 실시하였다.

\section{Results}

\section{주요변인의 상관관계}

본 연구에서 사용된 주요변인들의 영향에 관하여 상관분석을 실시하였다. 기초통계자료와 상관은 Table 1 에 제시된 바와 같 
Table 1

Descriptive Statistics for the Main Variables

\begin{tabular}{llllll}
\hline \multicolumn{1}{c}{ Variables } & $M$ & $S D$ & 1 & 2 \\
\hline 1 & Intellectual humility & 3.95 & 0.49 & & \\
2 & Self-development needs & 3.52 & 0.53 & $.37^{* * *}$ & $.31^{* * *}$ \\
3 & Teamwork & 3.6 & 0.48 & $.62^{* * *}$ & $.40^{* * *}$ \\
4 & Professional knowledge & 3.75 & 0.51 & $.45^{* * *}$ \\
\hline
\end{tabular}

Note. $N=206$.

${ }^{* *} p<.01 .{ }^{* * *} p<.001$.

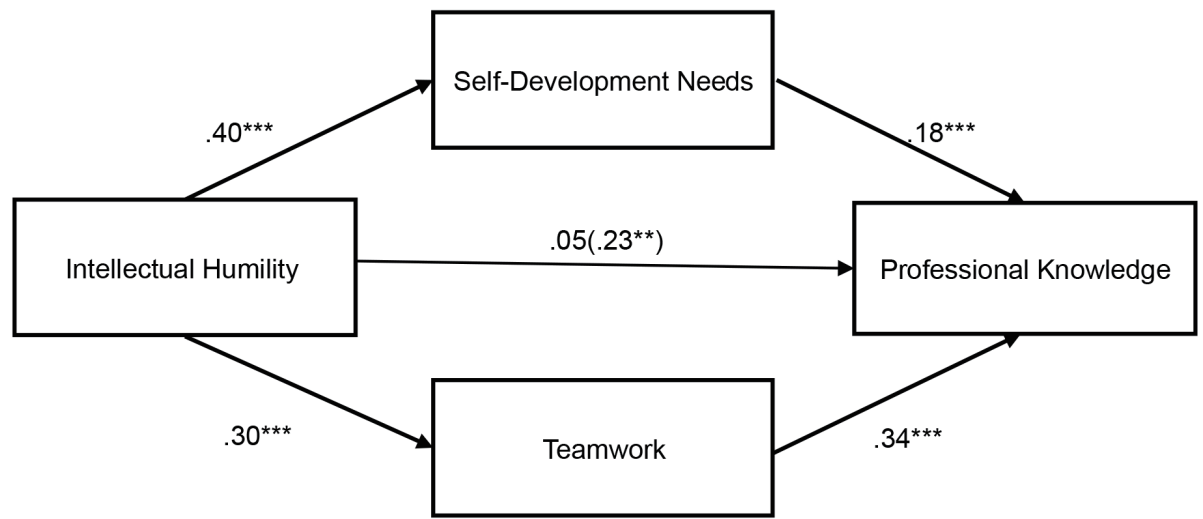

Figure 1. Path estimates (unstandardized) from double mediation model. Total effect is in the parenthesis.

${ }^{* *} p<.01 .{ }^{* * *} p<.001$.

다. 교사의 지적겸손 성향의 평균은 $3.95(S D=0.49)$, 자기개 발 욕구는 $3.52(S D=0.53)$, 동료교사 협력은 $3.60(S D=0.48)$, 전문적 지식은 $3.75(S D=0.51)$ 로 나타났다. 유아 교사의 지적 겸손 성향은 자기개발 욕구 $(r=.37, p<.001)$ 와 동료교사 협력 $(r=.31, p<.001)$, 전문적 지식 $(r=.22, p<.01)$ 과 정적인 상관 이 나타났다. 유아 교사의 자기개발 욕구 또한 동료교사 협력 $(r=.62, p<.001)$ 과, 전문적 지식 $(r=.40, p<.001)$ 과 정적인 상 관이 있는 것으로 나타났다. 마지막으로, 동료교사 협력과 전 문적 지식 역시 정적인 상관이 있었다 $(r=.45, p<.001)$.

\section{지적겸손 성향과 전문적 지식의 관계에서 자 기개발욕구와 동료교사 협력의 이중매개효과}

유아 교사의 지적겸손 성향이 전문적 지식에 미치는 영향에서 자기개발 욕구와 동료교사 협력의 이중매개효과를 알아보기 위해 PROCESS macro의 4번 모형을 이용하였다(Hayes, 2017; Preacher \& Hayes, 2004). 결과는 Figure 1과 Table 2에 나타난 바와 같다. 먼저, 유아 교사의 지적겸손 성향이 자기개발 욕구 로 가는 총 효과는 통계적으로 유의한 것으로 나타났으나 $(B=$ $.23, S E=.07,95 \%$ CI [.09-.36]), 자기개발 욕구와 동료교사 협
력을 통제한 후의 직접효과는 유의하지 않았다 $(B=.05, S E=$ $.07,95 \%$ CI [-.08-.19]). 둘째, 지적겸손 성향이 자기개발 욕구 를 예측하는 경로와 $(B=.40, S E=.07,95 \% \mathrm{CI}[.27-.54])$ 자기 개발 욕구가 전문적 지식을 예측하는 경로가 $(B=.18, S E=.08$, 95\% CI [.02-.33]) 모두 정적으로 유의하게 나타났다.

따라서, 지적겸손 성향에서 전문적 지식으로 가는 경로에 서 자기개발 욕구의 간접효과 역시 효과 역시 통계적으로 유 의하였다 $(B=.07, S E=.03,95 \% \mathrm{CI}$ [.01-.14]). 마지막으로 지적 겸손 성향이 동료교사 협력을 예측하는 경로와 $(B=.30, S E=$ $.06,95 \%$ CI [.17-.43]) 동료교사 협력이 전문적지식을 예측하 는 경로가 $(B=.34, S E=.08,95 \% \mathrm{CI}[.18-.51])$ 모두 정적으로 유의하게 나타났다. 이에, 지적겸손 성향에서 전문적 지식으 로 가는 경로에서 동료교사 협력의 간접효과 또한 통계적으로 유의하였다 $(B=.10, S E=.04,95 \%$ CI [.04-.19]).

\section{Discussion}

본 연구에서는 유아 교사의 지적겸손 성향과 전문적 지식의 관계를 알아보고, 그 관계에서 유아 교사의 자기개발 욕구와 
Table 2

Unstandardized Path Estimates for the Main Model

\begin{tabular}{|c|c|c|c|}
\hline Paths & $B(S E)$ & LLCI & ULCI \\
\hline Total effect: Intellectual humility $\rightarrow$ Professional knowledge & $.23(.07)$ & .09 & .36 \\
\hline Direct effect: Intellectual humility $\rightarrow$ Professional knowledge & $.05(.07)$ & -.08 & .19 \\
\hline Intellectual humility $\rightarrow$ Teamwork $\otimes$ Professional knowledge & $.10(.04)$ & .04 & .19 \\
\hline
\end{tabular}

동료교사 협력의 이중매개효과를 검증하고자 하였다. 본 연구 결과를 통해 지적겸손이라는 개념을 국내 학계에 소개하고 교 사에게 적용시켜 봄으로써, 지적겸손이 교사의 전문적 지식에 미치는 직·간접적 영향을 알아보고 그 기제를 밝히고자 하였 다. 본 연구의 주요 결과 및 논의는 다음과 같다.

첫째, 지적겸손 성향이 전문적 지식에 유의미한 영향을 미 치는 것으로 나타났다. 다시 말해, 유아 교사의 지적겸손 성향 이 높을수록 교사 스스로가 지각하는 전문적 지식 수준도 높 다는 것을 의미한다. 현재까지 유아 교사의 지적겸손 성향과 전문적 지식과의 관계를 직접적으로 탐색한 연구는 부재하다. 하지만, 지적겸손 성향이 높은 개인은 새로운 정보나 지식에 수용적인 태도를 보인다는 점에서 개방성과 개념적인 유사성 을 가진다. 개방성을 주제로 한 선행연구에 따르면 학교의 변 화에 개방적인 태도를 보이는 교사일수록, 개방적인 태도로 교수학습 과정에 유연하게 수행하는 교사일수록, 전문성 인 식도 높게 나타나며(Jeong, Hsiao, Song, Kim, \& Bae, 2016; Joo, Park, \& Hwang, 2015), 이러한 결과는 본 연구의 결과와 맥을 같이 한다. 현재까지 유아 교사의 전문성과 관련된 선행연구 들을 살펴보면 교사의 자질이나 효능감, 직무만족도 등과 같 이 직업적인 측면에서 교사가 느끼는 심리적 변인과 전문성 간의 관계 탐색이 주를 이루었고, 교사 개인 스스로에 대한 신 념과 태도에 관한 연구는 다소 미비한 실정이었다. 본 연구에 서는 지적겸손 성향이라는 새로운 성격 특성 변인을 소개하 고, 이 새로운 변인이 교사의 전문적 지식 지각에 미치는 영향 성을 검증했다는 점에서 의의가 있다.

둘째, 경로모형에서 교사의 지적겸손 성향은 자기개발욕구 를 통해 전문적 지식에 영향을 미치는 것으로 나타났다. 교사 의 지적겸손 성향이 강하고 높은 교사일수록 자기개발욕구가 높다는 것은 지적겸손 성향이 스스로의 학습에 대한 동기부 여를 일으켜 자기개발욕구를 향상했다고 해석할 수 있다. 선 행연구에서도 지적겸손 성향이 높은 사람은 새로운 학습정보 를 얻는 것에 흥미가 있으며 모르는 게 있으면 배워서 지식을 해소하려는 욕구도 더 큰 것으로 나타났다(Leary et al., 2017; Whitcomb, Battaly, Baehr, \& Howard-Snyder, 2017). 이와 같은
맥락에서 지적겸손 성향은 유아 교사로 하여금 전문적 지식 습득과 새로운 개념을 더 적극적으로 익히고 교사가 지녀야 할 능력을 더욱 높이고자 하는 내적 동기로 작용하여(Porter \& Schumann, 2018), 자기개발 욕구를 높인다고 볼 수 있다. 교사 의 이러한 자기개발 욕구는 다시 전문적 지식에 정적으로 유의 미한 영향을 미치는 것으로 나타났는데, 이는 교사의 자기개발 욕구가 높을수록 교사의 전문적 지식 수준이 높음을 의미한다. 이러한 결과는 교사의 자기개발 욕구와 전문성 간의 유의한 정 적인 상관관계를 나타낸 선행연구(J. R. Kim, 2008; S. A. Kim, 2005; Y. Kim, 2019; S. H. Lee, 2015)와 일치한다. 즉, 교사는 꾸 준히 자기개발을 위해 노력함으로써 자신의 전문적 지식 수준 을 성장시키고 질 높은 교육을 이룰 수 있음을 의미한다.

셋째, 자기개발 욕구와 더불어 동료교사 협력은 지적겸손 성향과 전문적 지식과의 관계를 매개하는 것으로 나타났다. 다시 말해, 지적겸손 성향이 높은 교사일수록 동료들과 원활 한 협력관계를 유지하고, 이는 전문적 지식의 향상으로 이어 진다는 것이다. 이러한 결과는 1980 년대 이후부터 이어져 온 학교현장에서의 교사들 간의 협력활동을 강조하는 움직임과 교사협력이 교사의 전문성 개발과 신장에 긍정적인 영향을 미친다는 실증연구와 일치한다(McLaughlin \& Talbert, 1993; Opfer \& Pedder, 2011; Song \& Park, 2016). 더불어, 본 연구 의 결과는 그간 선행 연구에서 밝힌 교사의 정서지능(Ryu \& Kang, 2015), 자기 장학(Oh, 2020) 이외에도 자신이 틀릴 수 있 음을 인정하고 타인의 의견에 개방적인 교사의 성격적 특성이 교육과 행정 업무에서 서로 도움을 주고받는 교사들의 협력관 계 형성에 긍정적인 영향을 미칠 수 있음을 시사한다.

지적겸손 성향, 자기개발 욕구, 동료교사 협력 등과 같은 정 의적인 요소들이 유아 교사의 전문적 지식에 미치는 영향성을 탐구한 본 연구 결과는 현재의 교사교육 프로그램에 시사하 는 바가 크다. 현재 이루어지고 있는 직무교육, 승급 교육 등의 필수 교사교육의 내용은 교육의 기술이나, 지식에 치우쳐있 다. 지적겸손, 자기개발과 같은 내적인 요인과 더불어 동료교 사 협력 등과 같은 대인관계 역량이 교사의 전문적 지식에 영 향을 미친다는 것을 검증한 본 결과는 교사의 전문성 향상을 
위해서 교사의 인성, 태도, 가치관, 신념 등을 함양하는 교육이 함께 이루어져야 함을 시사한다.

더불어, 개인적 차원에서 이루어지는 교사교육 못지않게 중요한 것은 지적겸손을 지향하는 조직문화를 만드는 것이다. 아무리 유익한 교육이라 할지라도 교사의 업무가 과중한 상태 에서 시행된다면 교사교육이 또 다른 일거리와 부담으로 전락 할 수 있다. 따라서 자신의 지적한계를 인식하고 타인의 의견 과 견해에 수용적인 조직문화 속에서 교사들이 자연스럽게 지 적겸손 성향을 도모할 수 있도록 하는 조직 수준의 노력이 필 요하다.

최근 개정된 누리과정과 표준보육과정은 유아 교사들에게 있어 과거의 수업방식과 놀이환경과는 다른 새로운 플랫폼을 제시한다. 가령, 개정된 누리과정에서는 유아.놀이 중심의 교 육과정 운영이 더욱 원활하게 이루어질 수 있도록 교사들끼리 정서적 지원과 배움을 나눌 수 있는 학습공동체를 자율적으로 구성할 것을 강조한다. 이러한 과도기적 시기에 자신이 모르 는 것을 인정하고 타인의 견해와 다양한 시각을 받아들이려는 교사의 지적겸손 성향은 변화된 환경과 교육과정에 적응하기 에 더없이 중요한 역량이다. 앞서 언급한 바와 같이 지적겸손 을 높일 수 있는 개인, 조직 수준의 노력이 함께 이루어진다면 새로운 교육과정과 환경에 대한 교사들의 불안과 혼란이 자신 감과 유능감에 한층 가까워질 수 있으리라 기대한다.

본 연구의 제한점과 후속연구를 위한 제언은 다음과 같다. 첫째, 본 연구가 지적겸손이라는 개념을 국내에 처음 소개하 는 연구이기에 미국인을 대상으로 Porter와 Schumann (2018) 이 개발한 원척도를 그대로 번역해서 사용하였다. 겸손함의 의미가 문화에 따라 다르게 받아들여지고 수용될 수 있다는 점을 고려해볼 때(Yamagishi et al., 2012), 후속 연구에서는 국 내 연구 참가자들을 대상으로 도구를 타당화할 필요가 있다. 둘째, 본 연구에서 사용된 모든 변인이 자기 보고식의 설문으 로 측정되었다. 자기보고식의 설문은 짧은 시간에 많은 정보 를 얻을 수 있다는 장점에도 불구하고 응답편향(response bias) 이 크게 나타난다(van de Mortel, 2008). 응답편향은 지적겸손, 자기개발 욕구, 전문적 지식과 같이 사회적으로 요구되는 바 람직한 답이 있을 때 더욱 크게 나타난다. 뿐만 아니라, 본 연 구에서 측정한 교사전문지식은 교사의 전문지식을 직접 측정 한 것이 아니라 교사가 ‘인식한’ 전문성이라는 점에서 한계가 있다. 따라서 후속연구에서는 관찰 및 행동측정 등과 같은 보 다 객관적이고 다각적인 자료수집 방법을 모색해 볼 필요가 있다. 셋째, 본 연구에서는 연구대상이 지원시설로 편중되어 있어, 근무환경에 따른 차이를 일반화하기 어렵다. 이에 후속
연구에서는 보다 다양한 지역과 근무기관 유형에 따른 폭넓은 연구를 진행할 필요가 있다.

\section{Conflict of Interest}

No potential conflict of interest relevant to this article was reported.

\section{Ethics Statement}

All procedures of this research were reviewed by IRB (201903-SB810-01).

\section{References}

\section{In English}

Ashton, M. C., \& Lee, K. (2007). Empirical, theoretical, and practical advantages of the HEXACO model of personality structure. Personality and Social Psychology Review, 11(2), 150-166. doi:10.1177/1088868306294907

Davis, D. E., Rice, K., McElroy, S., DeBlaere, C., Choe, E., van Tongeren, D. R., \& Hook, J. N. (2016). Distinguishing intellectual humility and general humility. The Journal of Positive Psychology, 11(3), 215-224. doi:10.1080/17439760 .2015 .1048818

Gilovich, T. D., \& Griffin, D. W. (2010). Judgment and decision making. In S. T. Fiske, D. T. Gilbert, G. Lindzey (Eds.), Handbook of social psychology (5th ed., Vol. 1, pp. 542588). Hoboken, NJ: John Wiley \& Sons.

Goddard, Y. L., Goddard, R. D., \& Tschannen-Moran, M. (2007). A theoretical and empirical investigation of teacher collaboration for school improvement and student achievement in public elementary schools. Teachers College Record, 109(4), 877-896.

Gregg, A. P., \& Mahadevan, N. (2014). Intellectual arrogance and intellectual humility: An evolutionary-epistemological account. Journal of Psychology and Theology, 42(1), 7-18. doi: $10.1177 / 009164711404200102$

Hayes, A. F. (2017). Introduction to mediation, moderation, and conditional process analysis: A regression-based approach (2nd ed.). New York: Guilford Press.

Jeong, S., Hsiao, Y.-Y., Song, J. H., Kim, J., \& Bae, S. H. (2016). The moderating role of transformational leadership on 
work engagement: The influences of professionalism and openness to change. Human Resource Development Quarterly, 27(4), 489-516. doi:10.1002/hrdq.21265

Koehler, D. J. (1991). Explanation, imagination, and confidence in judgment. Psychological Bulletin, 110(3), 499-519.

Krumrei-Mancuso, E. J. (2017). Intellectual humility and prosocial values: Direct and mediated effects. The Journal of Positive Psychology, 12(1), 13-28. doi:10.1080/17439760.2016.116 7938

Leary, M. R., Diebels, K. J., Davisson, E. K., Jongman-Sereno, K. P., Isherwood, J. C., Raimi, K. T.,...Hoyle, R. H. (2017). Cognitive and interpersonal features of intellectual humility. Personality and Social Psychology Bulletin, 43(6), 793-813. doi:10.1177/0146167217697695

Lindsay, P., \& Lindsay, C. H. (1987). Teachers in preschools and child care centers: Overlooked and undervalued. Child and Youth Care Quarterly, 16(2), 91-105.

McLaughlin, M. W., \& Talbert, J. E. (1993). Contexts that matter for teaching and learning: Strategic opportunities for meeting the nation's educational goals. Stanford, CA: Center for Research on the Context of Secondary School Teaching.

Moore, D. A., \& Healy, P. J. (2008). The trouble with overconfidence. Psychological Review, 115(2), 502-517. doi:10.1037/0033-295X.115.2.502

Opfer, V. D., \& Pedder, D. (2011). Conceptualizing teacher professional learning. Review of Educational Research, 81(3), 376-407. doi:10.3102/0034654311413609

Porter, T. (2015). Intellectual humility, mindset, and learning (Unpublished doctoral dissertation). Stanford University, CA.

Porter, T., \& Schumann, K. (2018). Intellectual humility and openness to the opposing view. Self and Identity, 17(2), 139-162. doi:10.1080/15298868.2017.1361861

Preacher, K. J., \& Hayes, A. F. (2004). SPSS and SAS procedures for estimating indirect effects in simple mediation models. Behavior Research Methods, Instruments, \& Computers, 36(4), 717-731.

Schaufeli, W. B., \& Greenglass, E. R. (2001). Introduction to special issue on burnout and health. Psychology \& Health, 16, 501-510. doi:10.1080/08870440108405523

van de Mortel, T. F. (2008). Faking it: Social desirability response bias in self-report research. Australian Journal of Advanced Nursing, 25(4), 40-48.

Whitcomb, D., Battaly, H., Baehr, J., \& Howard-Snyder, D. (2017). Intellectual humility: Owning our limitations. Philosophy and Phenomenological Research, 94(3). doi:10.1111/phpr.12228

Yamagishi, T., Hashimoto, H., Cook, K. S., Kiyonari, T., Shinada, M., Mifune, N.,... Li, Y. (2012). Modesty in selfpresentation: A comparison between the USA and Japan.
Asian Journal of Social Psychology, 15, 60-68. doi:10.1111/ j.1467-839X.2011.01362.x

\section{In Korean}

An, G.-Y. (1998). A speciality on the educare teacher of the time. The Korean Journal Child Education, 7(2), 149-162.

An, J. N. (2017). Relationship between perception of professionalism, job satisfaction and role performance of childcare teachers (Master's thesis). Retrieved from http://www.riss.kr/ link?id=T14569307

Cho, E.-J. (2012). The study of the child care teacher's professional recognition, job satisfaction and life satisfaction (Master's thesis). Retrieved from http://www.riss.kr/link?id=T12683764

Choi, J. E. (2018) The influences of the self-development desire of the childcare teachers on the interactions between the teacher and the little children: Centered on the mediating effects of the feeling of efficacy of the teachers (Master's thesis). Retrieved from http://www.riss.kr/link?id=T14937154

Choi, Y.-R. (2018). Interrelation among a perception to professionalism, an ego resilience and a feeling of happiness of infant teachers (Master's thesis). Retrieved from http://www.riss.kr/ link?id=T14771510

Jeon, E. M. (2017) Participation experience of teacher's learning community for elementary school teacher's improvement (Doctoral dissertation). Retrieved from http://www.riss.kr/ link?id=T14572336

Jeon, S. (2019). Relationship between professional development and self-development needs of childcare teachers (Master's thesis). Retrieved from http://www.riss.kr/link?id=T15353668

Joo, Y. H., Park, Y.-H., \& Hwang, H. S. (2015). The effects of child care-efficacy and creative personality on professional recognition of child care teachers. Journal of cognitive Enhancement and Intervention, 6(1), 93-109

Kang, U. J. (2015). The relationships among organizationalclimate, early childhood teachers' desire for selfdevelopment, and sense of happiness. Proceedings of 2015 Conference of the Korean Society for Early Childhood Education (p. 505). Seoul, Korea: KSECE. Retrieved from http://riss.kr/link?id=A101459460.

Kim, H.-J., \& Shin, E. (2008). The developmental levels of child care teachers' professionalism. The Journal of Korean Teacher Education, 25(3), 239-259. doi:10.24211/ tjkte.2008.25.3.239

Kim, J. (2017). A study on the relationship between professional recognition, teacher's happiness, and teacher-infant interaction of child care teachers (Master's thesis). Retrieved from http:// www.riss.kr/link?id=T14445974

Kim, J. (2019). The effects of the partnership with colleagues and parents on teaching efficacy in early childhood teachers 
(Master's thesis). Retrieved from http://www.riss.kr/ link?id=T15396012

Kim, J. M. (2019). The impact of childcare teachers' qualities and desire for self-development on their professionalism (Master's thesis). Retrieved from http://www.riss.kr/ link?id=T15308489

Kim, J. R. (2008). The relationship between teacher advance and self-improvent desire of physical education teacher (Master's thesis). Retrieved from http://www.riss.kr/ link?id=T11233025

Kim, M. (2011). A study on edu-care facilities' organizational culture and teachers' job satisfaction (Master's thesis). Retrieved from http://www.riss.kr/link?id=T12332568

Kim, S. A. (2005). The relationship between organizational culture in the school and teachers' need for self-development (Master's Thesis). Retrieved from http://www.riss.kr/ link?id=T10339359

Kim, S.-H. (2003). A study on the organizational climate and teachers' desire for self-development in an elementary school (Master's thesis). Retrieved from http://www.riss.kr/ link?id=T9165442

Kim, Y. (2019). The effects of self-development needs and childcare commitment on expertise development in childcare teachers (Master's thesis). Retrieved from http://www.riss.kr/ link?id=T15068463

Kim, Y. J. (2001). A study of reform measures on the childcare policy (Master's thesis). Retrieved from http://www.riss.kr/ link?id=T8343900

Kwon, S.-H., \& Kim, D.-K. (2013). A study on development and validity of the teacher collaboration scale. The Journal of Educational Administration, 31(1), 109-132.

Kwon, S.-H., \& Kim, D.-K. (2014). The structural relationship among collective teacher efficacy, personal teacher efficacy and teacher-collaboration. The Journal of Korean Teacher Education, 31(2),161-180.

Kwon, Y. (2013). The relationship between early childhood teachers' expertise development and job satisfaction (Master's thesis). Retrieved from http://www.riss.kr/link?id=T13126205

Lee, J. (2010). A study on the infant nursing teacher's recognition of professionalism and job satisfaction (Master's thesis). Retrieved from http://www.riss.kr/link?id=T11921885

Lee, J. (2014). The mediating effects of teacher's followership and teacher's colleagueship in the relationship between principal's transformational leadership and school organizational effectiveness (Doctoral dissertation). Retrieved from http:// www.riss.kr/link?id=T13548014

Lee, J. M. (2017). Relationships between perfectionism tendencies, beliefs about teaching and learning and perceived role performance of early childhood educators (Master's thesis). Retrieved from http://www.riss.kr/link?id=T14462185
Lee, M.-S. (2002). The potential of partnership teaching in early childhood education. Journal of Young Child Studies, 5, 5-22.

Lee, S. H. (2011). Teaching and learning climate in childcare facilities, teachers' perception of expertise, and operations of childcare curriculum (Master's thesis). Retrieved from http:// www.riss.kr/link?id=T12321365

Lee, S. H. (2015). The influence of child care teacher's teacher efficacy and work environment on desire for self-development (Master's thesis). Retrieved from http://www.riss.kr/ link?id=T13849545

Lee, S.-W. (2020). The effects of humility in leadership on jobrelated self-efficacy and customer orientation in hotels. Journal of Hospitality and Tourism Studies, 22(2), 96-107.

Lee, Y. S. (2001). School management and School-Based Autonomous Supervision (SBAS). Seoul: Kyoyookkwahaksa.

Oh, E. (2020). The influence of peer-supervision and selfsupervision on teacher professionalism through teacher learning community. Journal of Social Sciences, 13(1), 123153.

Park, B. Y. (2013). Experience search of elementary school teacher's self-development activities (Master's thesis). Retrieved from http://www.riss.kr/link?id=T13092190

Park, E. Y. (2018). The self-development needs and professional perceptions of teachers and directors in day care center (Master's thesis). Retrieved from http://www.riss.kr/ link?id=T14761546

Park, J. H., Song, I. B., \& Lee, J. Y. (2016). The impact of teacher collaboration as a learning activity on teaching practices. The Journal of Korean Teacher Education, 33(1), 243-265.

Park, S. (2019). The effects of teaching efficacy and expertise awareness on happiness in preschool teachers (Master's thesis). Retrieved from http://www.riss.kr/link?id=T15068478

Park, Y. S., Song, S. M., \& Lee, S. R. (2018). The mediating effects of public type child care center teachers' professional perception on the relationship between teachers' job satisfaction and teacher-child interaction. Journal of Lifespan Studies, 8(1), 1-16.

Ryu, K.-H., \& Kang, S. (2015). Analysis of structural model of emotional intelligence, co-teachers' cooperative relationship, parent-teacher cooperative relationship, and teacher's efficacy. Journal of Early Childhood Education \& Educare Welfare, 19(2), 203-225.

Son, M. H. (2014). The effects of early childhood teachers' professional recognition and teacher-efficacy on children's learning behavior (Master's thesis). Retrieved from http://www.riss.kr/ link?id=T13552234

Song, I.-B., \& Park, J.-H. (2016). Development of the questionnaire measuring teacher collaboration activities leading to teaching professional. Asian Journal of Education, 
$17(1), 225-249$.

Sung, J. (2018). Structural relationship among nursery school teacher job satisfaction, awareness of professionalism, collaboration, and nursery school effectiveness. The Journal of Eco Early Childhood Education \& Care, 17(3), 25-47.

Yoon, O.-Y. (2017). A study on the job attitude and professional perception of child care teacher: Focusing on the child care teacher of daycare center in Seoul (Master's thesis). Retrieved from http://www.riss.kr/link?id=T14428368

You, J. Y. (2011). The effects ego-resilience and occupational stress on professionalism awareness in early childhood teachers (Master's thesis). Retrieved from http://www.riss.kr/ link?id=T12341612

\section{ORCID}

Yumi Kim https://orcid.org/0000-0002-8807-0622

Daeun Park https://orcid.org/0000-0003-1371-9121

Revision received April 4, 2021

Accepted April 5, 2021 